\title{
Physiotherapy Management of Patients with COVID-19 Infection in a Tertiary Care Setup- A Case Series
}

\author{
Gauri Wakde1, Prajakta Patil², Sumit Jadhav, Zahara Polen, \\ Pranali Shamkure ${ }^{5}$
}
${ }^{1}$ MPT Cardiovascular and Respiratory Physiotherapy, Smt. Kashibai Navale College of Physiotherapy, Narhe, Pune, India.
${ }^{2}$ Professor and HOD, Cardiovascular and Respiratory Physiotherapy, Smt. Kashibai Navale College of Physiotherapy, Narhe, Pune, India.
${ }^{3}$ Postgraduate Student, Smt. Kashibai Navale College of Physiotherapy, Narhe, Pune, India.
${ }^{4}$ Assistant Professor, Cardiovascular and Respiratory Physiotherapy, Smt. Kashibai Navale College of Physiotherapy, Narhe, Pune, India.

${ }^{5}$ MPT Cardiovascular and Respiratory Physiotherapy, Smt. Kashibai Navale College of Physiotherapy, Narhe, Pune, India.

\begin{abstract}
The entire world is currently in the clutches of COVID-19. COVID-19 has led to major health crises in the world. Inadequate hospital facilities, shortage of medications, constantly rising cases and increasing death rates have created fear and panic amongst the people. Patients having comorbidities develop more severe form of disease and require longer time for recovery. This case series highlights the patients with comorbidities who represented moderate to severe infection. However Physiotherapy interventions right from the beginning along with medical management resulted in remarkable recovery of the patients. This proves the vital role of physiotherapy in COVID-19. Such positive outcomes appeal including physiotherapy along with medical management for every patient with COVID-19.
\end{abstract}

Keywords: COVID-19, Coronavirus, Case series, Comorbidities, moderate to severe symptoms, physiotherapy

\section{INTRODUCTION}

Coronavirus disease 2019 (COVID19) caused by SARS-COV2 emerged from Wuhan on $17^{\text {th }}$ November 2019, which became a worldwide pandemic. Even after a year, it continues to rapidly sweep creating havoc causing major public health and economic crises across the world. (1)

COVID 19 is highly transmittable pathogenic disease currently having 146 million cases over the globe with 16.6 million cases in India with the numbers rising rapidly (As of $25^{\text {th }}$ April 2021). The morbidity and mortality of the disease is dramatically increasing.

Infection to susceptible individual can be transmitted directly when the person comes in contact with an infected symptomatic or asymptomatic individual. (2) Aerosols, droplets and fomites became vital routes of direct transmission. ${ }^{(3)}$ Indirect transmission occurs mainly by fomites, when the people in the vicinity of these surroundings use infected objects. ${ }^{(4,5)}$

Virus binds to epithelial cells in nasal cavity and starts replicating via ACE2 receptor. Later the virus is propagated down 
the airways triggering more robust immune response. The virus gradually reaches the alveoli causing alveolar damage with hyaline membrane \& giant cells causing pneumonia, and ARDS in severe cases, which heals by fibrosis. ${ }^{(6)}$

COVID 19 has an incubation of is 3-

7 days (median 5.1 days) and maximum up to 2 weeks form infection with average of $12.5 / 11.5$ days in $97.5 \%$ of patients. COVID 19 symptoms include fever/chills (89\%), cough (68\%), fatigue (38\%), sputum production (34\%), dyspnoea (19\%), muscle/ body aches, and headache, new loss of taste or smell, sore throat, congestion /runny nose, nausea /vomiting, diarrhoea.COVID19 mainly affects the lungs. However it also can cause cardiac, haematological, neurological, gastrointestinal, renal and liver dysfunctions. ${ }^{(7,8)}$ Severe form of COVID 19 can hit patients with comorbidities like hypertension and diabetes.

COVID 19 patients usually present with a debilitated physical condition due to fever, fatigue, myalgia which further reduces their exercise capacity, which causes prolonged immobilization. Significant decrease in activity levels lead to reduction in muscle strength and cardiorespiratory endurance. ${ }^{(9)}$ Even after discharge altered quality of life is observed among $44.1 \%$ of patients, with persistence of least 1 symptom post COVID 19. Around $87.4 \%$, patients particularly report fatigue (53.1\%) and dyspnoea (43.4\%) two months post COVID 19. Other symptoms include joint pain, (27.3\%) and chest pain (21.7\%). (10) Hence physiotherapy becomes significantly important right from the beginning and even post COVID in order to initiate early mobilization and prevent complications which gradually progresses to regaining of strength and recovery to ADLs (11) Physiotherapy in COVID is proved to be preventive and curative which includes respiratory care, postural changes, breathing exercises, dyspnoea relieving positions, limb mobility, relaxation exercises, and ambulation of patients.
The aim of this article is to highlight the importance and benefits of Physiotherapy interventions in the management of COVID 19 patients. All the patients in this case series showed significant improvement in response to physiotherapeutic interventions.

\section{CASE PRESENTATION}

Case Study 1: A 56 year old male with known case of diabetes was admitted to COVID ICU on $4^{\text {th }}$ day of onset of symptoms on $8^{\text {th }}$ January 2021 . He was initially on NIV for 4 days on Fio 2 of $60 \%$ and later on $8 \mathrm{~L} / \mathrm{min} \mathrm{O} 2$ via simple face mask. His laboratory studies showed increased ferritin level $515 \mathrm{mcg} / \mathrm{L}$ and CRP was $19.9 \mathrm{mg} / \mathrm{L}$. HRCT showed multiple ground glass opacities bilaterally, scarring with traction bronchiectasis bilaterally, right pneumothorax and patchy consolidation in right upper lobe and lower lobe. Patient was given breathing exercises, CARP protocol, bed side mobility exercises and progressed gradually to standing and spot marching while on oxygen flow of $3 \mathrm{~L} / \mathrm{min}$ via nasal prongs. Exercises were continued with same intensity until the patient was taken off $\mathrm{O} 2$ after 4 days. Ambulation was given with breathing control as tolerated and the distance was subsequently increased. Stair climbing was initiated simultaneously as the patient shifted to non COVID ward. The patient was subsequently discharged after all the vitals came normal.

Case Study 2: A 64 year old male with known case of diabetes and hypertension was admitted to COVID ICU on $5^{\text {th }}$ January. Initially patient was on $90 \%$ NIV whereby patient was given breathing exercise, CARP and advice to repeat it twice daily. On $19^{\text {th }}$ January 2021 patient was shifted from COVID ICU to non COVID ICU after which he was on $15 \mathrm{~L} / \mathrm{min}$ of $\mathrm{O} 2$ via nonrebreathing mask. His laboratory studies showed increased ferritin level $420 \mathrm{mcg} / \mathrm{L}$ and increased CRP 20.2. His chest X-ray showed haziness in bilateral lower zones. The patient was monitored initially for few 
minutes while he performed CARP protocol under supervision. Patient was given breathing exercises and mobility exercises with bedside sitting. Ambulation with breathing control was started within a week in ICU. Ambulation was performed around the bed with $\mathrm{O} 2$ which was progressed to level walking of around 50 meters without $\mathrm{O} 2$ initially. The patient was monitored for any signs of dyspnoea or desaturation during ambulation without $\mathrm{O} 2$. The patient's $\mathrm{O} 2$ requirement was decreased up to $3 \mathrm{~L} / \mathrm{min}$ when he was shifted to Non COVID ward and tapered to $2 \mathrm{~L} / \mathrm{min}$ before he was discharged from the hospital. The patient was given interval training with adequate rest periods. The patient was discharged subsequently and continued physiotherapy for post COVID rehabilitation whereby stair climbing and strengthening was given.

Case Study 3: A 65 year old male with hypertension was admitted in COVID ICU on $17^{\text {th }}$ January 2021 . He was on noninvasive ventilation with $60 \% \mathrm{FiO} 2$. His laboratory studies showed increased ferritin level $432 \mathrm{mcg} / \mathrm{L}$ and increased CRP 18.4. The patient was given breathing exercises and lateral positioning in COVID ICU. Patient was shifted to COVID ward on $20^{\text {th }}$ January 2021. He was on was on $5 \mathrm{~L} / \mathrm{min}$ O2 via simple face mask when the rehabilitation started in the ward. Supplemental O2 was reduced gradually as the exercise tolerance of the patient was increased. The patient was maintaining $95 \%$ of $\mathrm{SpO} 2$ on $5 \mathrm{~L} / \mathrm{min} \mathrm{O} 2$. The patient was also given awake prone positioning. Subsequently standing, spot marching and ambulation was incorporated in the protocol. The patient felt relief from dyspnoea when he was taught breathing control with ambulation. The patient was also started climbing 1 flight of stairs within 1 week of rehabilitation which progressed gradually when patient was shifted to non COVID ward. Baseline Spo2 was increased to $95 \%$ at rest and the recovery time was decreased to less than 1 minute during the latter part of the rehabilitation. The patient was discharged on $3^{\text {rd }}$ February 2021.

Case Study 4: A 58 year old male patient with diabetes and hypertension was shifted to COVID ICU on $29^{\text {th }}$ January 2021. His ferritin levels were $500 \mathrm{mcg} / \mathrm{L}$ and CRP was 20.The patient was initially on $80 \%$ NIV during which CARP, breathing exercises and mobility exercises were given. Subsequently the patient improved and was taken on partial rebreathing mask with 12 $\mathrm{L} / \mathrm{min}$ of $\mathrm{O} 2$. He was progressed to bed side sitting and sit to stand in addition to breathing exercises and CARP protocol. Later oxygen was reduced to $2 \mathrm{~L} / \mathrm{min} \mathrm{O} 2$ via nasal cannula in the COVID ward. Patient shifted to non COVID ward on $12^{\text {th }}$ February were exercises were progressed to squatting and spot marching with oxygen therapy. As the oxygenation improved, patient was able to maintain the Spo2 within the normal limits after which ambulation was started. Stair climbing was also included in the protocol subsequently. Patient was discharged on $17^{\text {th }}$ February when patient stabilized and continued post COVID rehabilitation.

Case Study 5: A 71 year old female with hypertension, obesity was admitted to COVID ICU on $28^{\text {th }}$ January 2021 where the patient was on $90 \%$ NIV. Her ferritin level was $520 \mathrm{mcg} / \mathrm{L}$ and CRP was 22 . Patient was given CARP protocol, breathing exercises and mobility exercises. Patient was shifted to MICU on $13^{\text {th }}$ February 2021 where patient was on $50 \%$ NIV. The previous exercise protocol continued along with bed side sitting and sit to stand. Later on after 4 days, patient was shifted to non COVID ward where she was started spot marching with $6 \mathrm{~L} / \mathrm{min} \mathrm{O} 2$ via nasal cannula. After 3 days, exercises were progressed to ambulation with breath control with $2 \mathrm{~L} / \mathrm{min}$. O2. Gradually stair climbing was initiated. As the vitals stabilized, patient was discharged and continued post COVID rehabilitation. 
Gauri Wakde et.al. Physiotherapy management of patients with COVID-19 infection in a tertiary care setup- a case series.

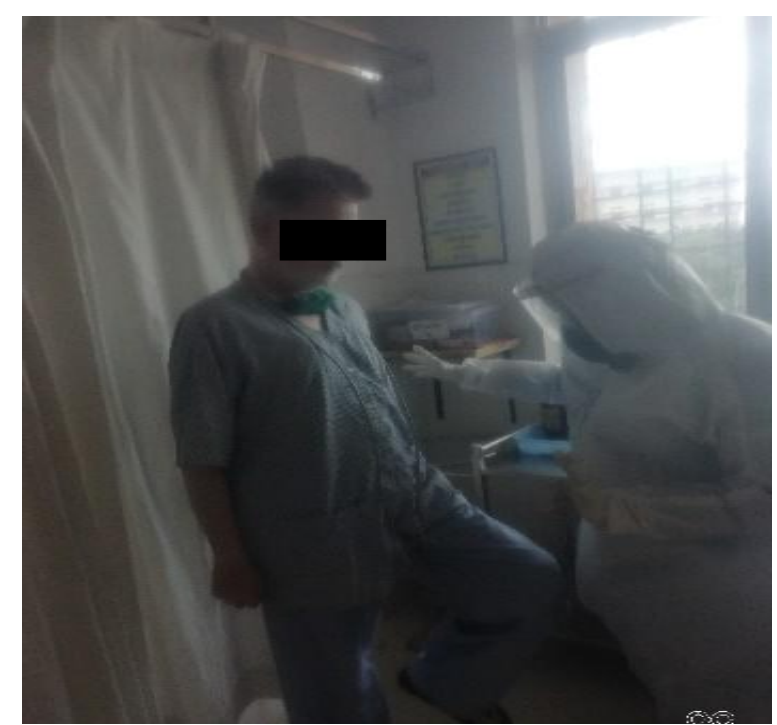

Fig 1-Spot marching

Table 1- Case study 1

\begin{tabular}{|l|l|l|l|l|l|}
\hline Days & $\mathbf{1}$ & $\mathbf{2}$ & $\mathbf{3}$ & $\mathbf{4}$ & $\mathbf{5}$ \\
\hline O2 Supply & NIV & NIV & 8L & 3L & Nil \\
\hline PR (bpm) Pre & & $\mathbf{9 3}$ & $\mathbf{9 2}$ & $\mathbf{9 4}$ & $\mathbf{9 1}$ \\
\hline \multicolumn{1}{|c|}{ Post } & & $\mathbf{9 7}$ & $\mathbf{9 6}$ & $\mathbf{9 5}$ & $\mathbf{9 8}$ \\
\hline RR (bpm) Pre & & $\mathbf{2 0}$ & $\mathbf{1 9}$ & $\mathbf{2 1}$ & $\mathbf{2 0}$ \\
\hline \multicolumn{1}{|c|}{ Post } & & $\mathbf{2 2}$ & $\mathbf{2 3}$ & $\mathbf{2 4}$ & $\mathbf{2 3}$ \\
\hline Pre & & $\mathbf{9 1}$ & $\mathbf{9 1}$ & $\mathbf{9 2}$ & $\mathbf{9 4}$ \\
\hline \multicolumn{1}{|c|}{ Post } & & $\mathbf{9 3}$ & $\mathbf{9 4}$ & $\mathbf{9 6}$ & $\mathbf{9 8}$ \\
\hline Positioning & $\checkmark$ & $\checkmark$ & $\checkmark$ & $\checkmark$ & $\checkmark$ \\
\hline Breathing Exs & $\checkmark$ & $\checkmark$ & $\checkmark$ & $\checkmark$ & $\checkmark$ \\
\hline Exs in sitting & $\checkmark$ & $\checkmark$ & $\checkmark$ & $\checkmark$ & $\checkmark$ \\
\hline $\begin{array}{l}\text { Incentive } \\
\text { Spirometry }\end{array}$ & & & $\checkmark$ & $\checkmark$ & $\checkmark$ \\
\hline Sit to stand & & & $\checkmark$ & $\checkmark$ & $\checkmark$ \\
\hline Spot marching & & & $\checkmark$ & $\checkmark$ & $\checkmark$ \\
\hline Ambulation & & & $\checkmark$ & $\checkmark$ & $\checkmark$ \\
\hline Stair climbing & & & & $\checkmark$ & $\checkmark$ \\
\hline
\end{tabular}

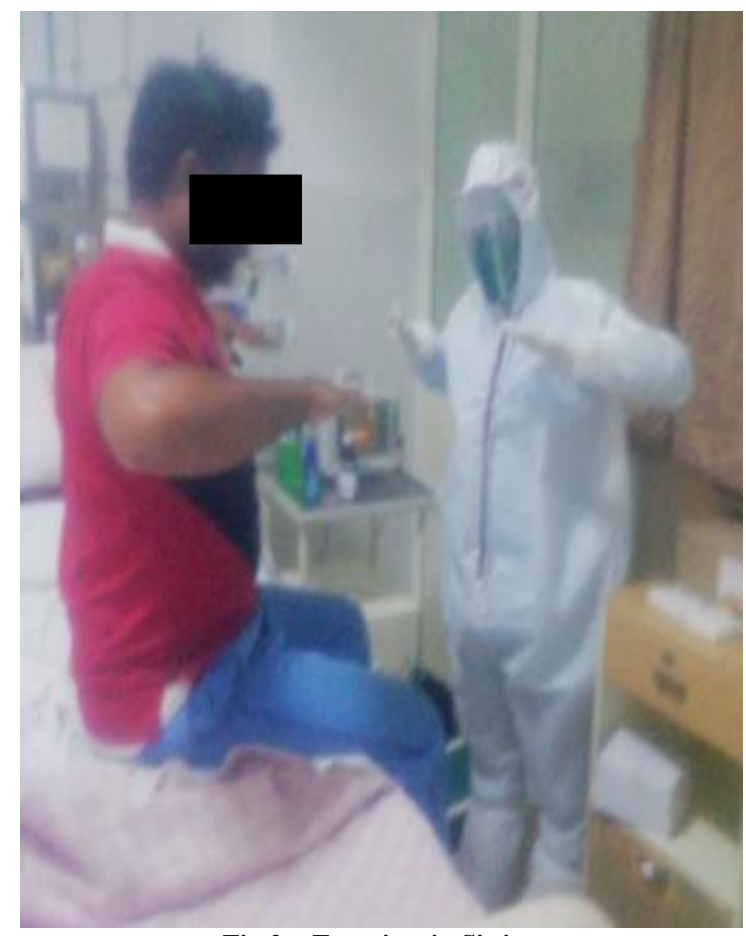

Fig 2- Exercises in Sitting
Table 2- Case study 2

\begin{tabular}{|c|c|c|c|c|c|}
\hline Days & 1 & 2 & 3 & 4 & 5 \\
\hline O2 Supply & NIV & NIV & $15 \mathrm{~L}$ & $4 \mathrm{~L}$ & Nil \\
\hline PR (bpm) Pre & & 115 & 116 & 113 & 114 \\
\hline Post & & 112 & 114 & 111 & 112 \\
\hline RR (bpm) Pre & & 20 & 19 & 21 & 20 \\
\hline Post & & 22 & 23 & 24 & 23 \\
\hline SpO2 & & 89 & 90 & 92 & 93 \\
\hline Post & & 93 & 94 & 93 & 95 \\
\hline Positioning & $\checkmark$ & $\checkmark$ & $\checkmark$ & $\checkmark$ & $\checkmark$ \\
\hline Breathing Exs & $\checkmark$ & $\checkmark$ & $\checkmark$ & $\checkmark$ & $\checkmark$ \\
\hline Exs in sitting & $\checkmark$ & $\checkmark$ & $\checkmark$ & $\checkmark$ & $\checkmark$ \\
\hline $\begin{array}{l}\text { Incentive } \\
\text { Spirometry }\end{array}$ & & & $\checkmark$ & $\checkmark$ & $\checkmark$ \\
\hline Sit to stand & & & $\checkmark$ & $\checkmark$ & $\checkmark$ \\
\hline Spot marching & & & $\checkmark$ & $\checkmark$ & $\checkmark$ \\
\hline Ambulation & & & $\checkmark$ & $\checkmark$ & $\checkmark$ \\
\hline Stair climbing & & & & $\checkmark$ & $\checkmark$ \\
\hline
\end{tabular}

Table 3- Case study 3

\begin{tabular}{|l|l|l|l|l|l|}
\hline Days & $\mathbf{1}$ & $\mathbf{2}$ & $\mathbf{3}$ & $\mathbf{4}$ & $\mathbf{5}$ \\
\hline O2 Supply & NIV & NIV & 5L & Nil & Nil \\
\hline PR (bpm) Pre & & $\mathbf{9 8}$ & $\mathbf{1 0 7}$ & $\mathbf{1 0 5}$ & $\mathbf{9 1}$ \\
\hline Post & & $\mathbf{7 8}$ & $\mathbf{1 0 2}$ & $\mathbf{1 1 0}$ & $\mathbf{8 8}$ \\
\hline RR (bpm) Pre & & $\mathbf{2 4}$ & $\mathbf{2 2}$ & $\mathbf{2 3}$ & $\mathbf{2 1}$ \\
\hline \multicolumn{1}{|c|}{ Post } & & $\mathbf{2 0}$ & $\mathbf{1 9}$ & $\mathbf{2 0}$ & $\mathbf{1 8}$ \\
\hline Pre & & $\mathbf{9 6}$ & $\mathbf{9 3}$ & $\mathbf{9 5}$ & $\mathbf{9 7}$ \\
\hline \multicolumn{1}{|c|}{ Post } & & $\mathbf{9 8}$ & $\mathbf{9 8}$ & $\mathbf{9 9}$ & $\mathbf{9 8}$ \\
\hline Positioning & $\checkmark$ & $\checkmark$ & $\checkmark$ & $\checkmark$ & $\checkmark$ \\
\hline Breathing Exs & $\checkmark$ & $\checkmark$ & $\checkmark$ & $\checkmark$ & $\checkmark$ \\
\hline Exs in sitting & $\checkmark$ & $\checkmark$ & $\checkmark$ & $\checkmark$ & $\checkmark$ \\
\hline $\begin{array}{l}\text { Incentive } \\
\text { Spirometry }\end{array}$ & & & $\checkmark$ & $\checkmark$ & $\checkmark$ \\
\hline Sit to stand & & & $\checkmark$ & $\checkmark$ & $\checkmark$ \\
\hline Spot marching & & & $\checkmark$ & $\checkmark$ & $\checkmark$ \\
\hline Ambulation & & & $\checkmark$ & $\checkmark$ & $\checkmark$ \\
\hline Stair climbing & & & & $\checkmark$ & $\checkmark$ \\
\hline
\end{tabular}

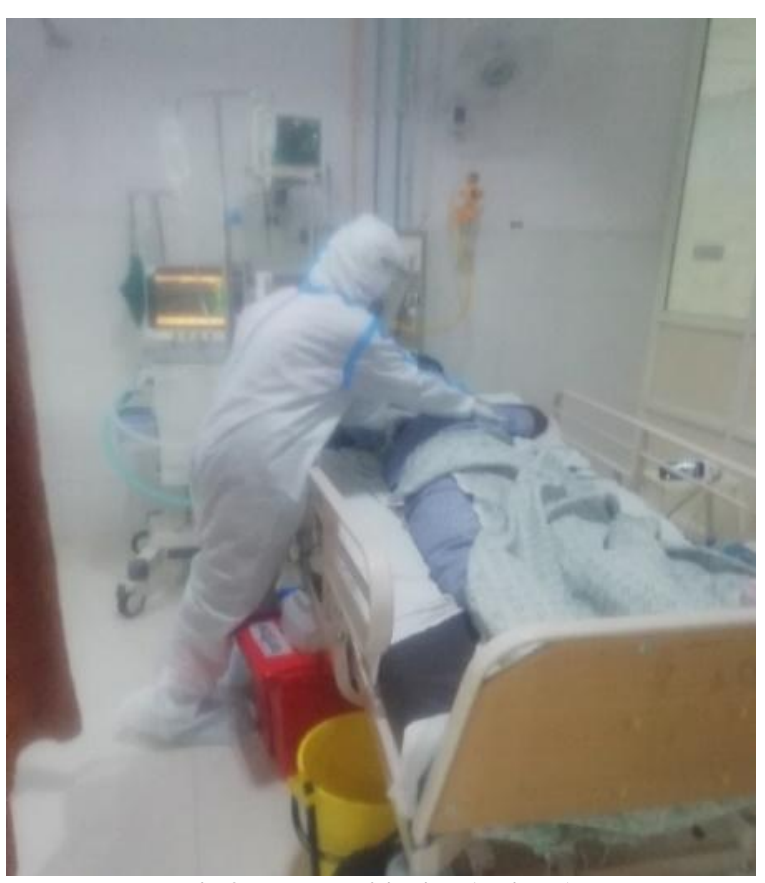

Fig 3-Prone positioning (assisted) 
Gauri Wakde et.al. Physiotherapy management of patients with COVID-19 infection in a tertiary care setup- a case series.

Table 4- Case study 4
\begin{tabular}{|l|l|l|l|l|l|}
\hline Days & $\mathbf{1}$ & $\mathbf{2}$ & $\mathbf{3}$ & $\mathbf{4}$ & $\mathbf{5}$ \\
\hline O2 Supply & NIV & $\mathbf{1 2 L}$ & $\mathbf{2 L}$ & Nil & Nil \\
\hline PR (bpm) Pre & & $\mathbf{9 8}$ & $\mathbf{1 0 7}$ & $\mathbf{1 0 5}$ & $\mathbf{9 1}$ \\
\hline \multicolumn{1}{|c|}{ Post } & & $\mathbf{7 8}$ & $\mathbf{1 0 2}$ & $\mathbf{1 1 0}$ & $\mathbf{8 8}$ \\
\hline RR (bpm) Pre & & $\mathbf{2 4}$ & $\mathbf{2 2}$ & $\mathbf{2 3}$ & $\mathbf{2 1}$ \\
\hline \multicolumn{1}{|c|}{ Post Pre } & & $\mathbf{2 0}$ & $\mathbf{1 9}$ & $\mathbf{2 0}$ & $\mathbf{1 8}$ \\
\hline SpO2t & & $\mathbf{9 6}$ & $\mathbf{9 3}$ & $\mathbf{9 5}$ & $\mathbf{9 7}$ \\
\hline \multicolumn{1}{|c|}{ Post } & $\checkmark$ & $\checkmark$ & $\checkmark$ & $\checkmark$ & $\checkmark$ \\
\hline Positioning & $\checkmark$ & $\checkmark$ & $\checkmark$ & $\checkmark$ & $\checkmark$ \\
\hline Breathing Exs & $\checkmark$ & $\checkmark$ & $\checkmark$ & $\checkmark$ & $\checkmark$ \\
\hline Exs in sitting & & $\checkmark$ & $\checkmark$ & $\checkmark$ & $\checkmark$ \\
\hline $\begin{array}{l}\text { Incentive } \\
\text { Spirometry }\end{array}$ & & & & & \\
\hline Sit to stand & & & $\checkmark$ & $\checkmark$ & $\checkmark$ \\
\hline Spot marching & & & $\checkmark$ & $\checkmark$ & $\checkmark$ \\
\hline Ambulation & & & $\checkmark$ & $\checkmark$ & $\checkmark$ \\
\hline Stair climbing & & & & $\checkmark$ & $\checkmark$ \\
\hline
\end{tabular}

Table 5- Case study 5
\begin{tabular}{|l|l|l|l|l|l|}
\hline Days & $\mathbf{1}$ & $\mathbf{2}$ & $\mathbf{3}$ & $\mathbf{4}$ & $\mathbf{5}$ \\
\hline O2 Supply & NIV & NIV & $\mathbf{6 L}$ & $\mathbf{2 L}$ & Nil \\
\hline PR (bpm) Pre & & $\mathbf{1 1 0}$ & $\mathbf{1 0 8}$ & $\mathbf{1 0 9}$ & $\mathbf{1 0 0}$ \\
\hline \multicolumn{1}{|c|}{ Post } & & $\mathbf{9 7}$ & $\mathbf{9 6}$ & $\mathbf{9 5}$ & $\mathbf{9 8}$ \\
\hline RR (bpm) Pre & & $\mathbf{2 0}$ & $\mathbf{1 9}$ & $\mathbf{2 1}$ & $\mathbf{2 0}$ \\
\hline \multicolumn{1}{|c|}{ Post } & & $\mathbf{2 2}$ & $\mathbf{2 3}$ & $\mathbf{2 4}$ & $\mathbf{2 3}$ \\
\hline Pre & & $\mathbf{8 9}$ & $\mathbf{9 0}$ & $\mathbf{9 2}$ & $\mathbf{9 4}$ \\
\hline \multicolumn{1}{|c|}{ Post } & & $\mathbf{9 3}$ & $\mathbf{9 4}$ & $\mathbf{9 6}$ & $\mathbf{9 8}$ \\
\hline Positioning & $\checkmark$ & $\checkmark$ & $\checkmark$ & $\checkmark$ & $\checkmark$ \\
\hline Breathing Exs & $\checkmark$ & $\checkmark$ & $\checkmark$ & $\checkmark$ & $\checkmark$ \\
\hline Exs in sitting & $\checkmark$ & $\checkmark$ & $\checkmark$ & $\checkmark$ & $\checkmark$ \\
\hline $\begin{array}{l}\text { Incentive } \\
\text { Spirometry }\end{array}$ & & & $\checkmark$ & $\checkmark$ & $\checkmark$ \\
\hline Sit to stand & & & $\checkmark$ & $\checkmark$ & $\checkmark$ \\
\hline Spot marching & & & $\checkmark$ & $\checkmark$ & $\checkmark$ \\
\hline Ambulation & & & $\checkmark$ & $\checkmark$ & $\checkmark$ \\
\hline Stair climbing & & & & $\checkmark$ & $\checkmark$ \\
\hline
\end{tabular}

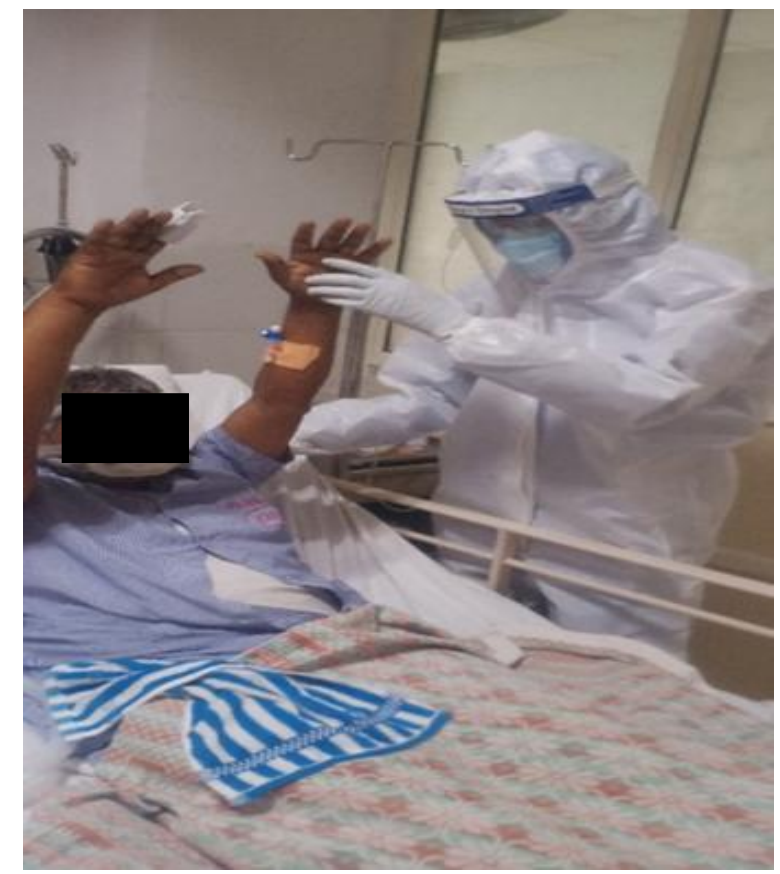

Fig 4- In bed mobility

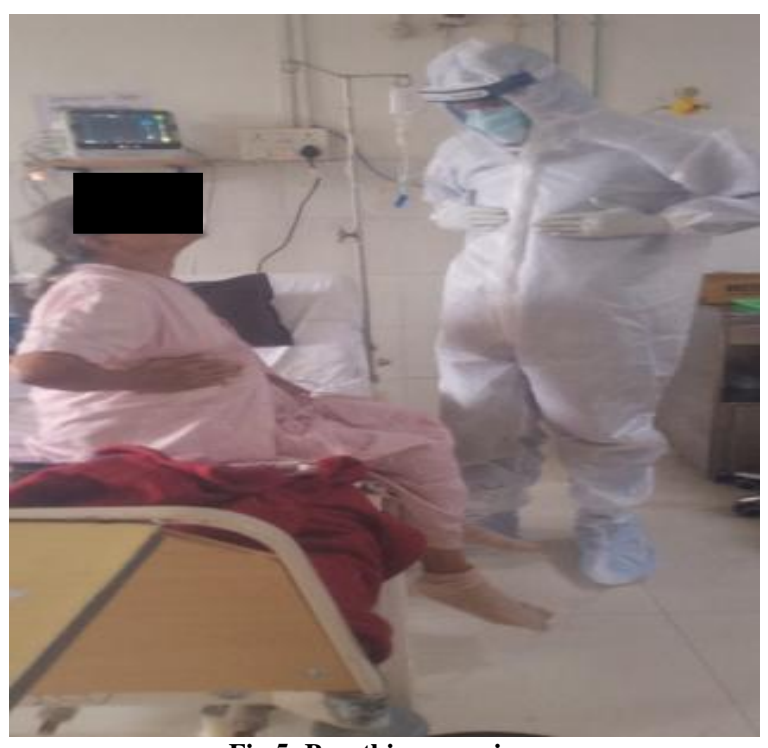

Fig 5- Breathing exercises

\section{DISCUSSION}

COVID-19 is an exceedingly transmittable viral infection which has led to major health crises in the world. Lack of medications, hospital facilities and constantly rising cases have created anxiety and panic amongst the people. Inadequate medical facilities worsen the condition of the patients.

More often patients commute to the hospital with pneumonia, ARDS, sepsis and septic shock. Due to scarcity of resources and delay in hospitalization around 9 to $14 \%$ of patients develop moderate to severe disease and require oxygen support while $5 \%$ of patients become critical requiring ICU admission and subsequently intubation and ventilation. ${ }^{(12)}$

Patients having comorbidities develop more severe form of disease and require longer time for recovery due to decline in innate immunity because of age and comorbidities. ${ }^{(\mathbf{1 3})}$

This case series highlights the patients with comorbidities who represented moderate to severe infection. However Physiotherapy interventions right from the beginning along with medical treatment and post COVID rehabilitation post discharge of patients led to significant recovery and improvement in quality of life of all the patients.

Such significant improvements throw a light over importance of physiotherapy and help to restore faith and instil confidence about health care system in patients in these tough times. 
Patients were given physiotherapy since the day of admission. The anxiety and fear of COVID 19 was reduced by education and counselling. Patients were monitored regularly based on vitals, breathing pattern, and use of accessory muscles and dyspnoea on NRS at rest and at activity.

The primary goal of Physiotherapy was to wean patients off the ventilator, early mobilization and preventing complications and accumulation of bronchopulmonary secretions.

Breathing exercises led to improvement in oxygenation and reduced respiratory rate. Positioning resulted in improving hypoxaemia, prevented atelectasis, optimized ventilation and prevented pressure sores. (14) Mobility exercises helped to prevent complications of bed rest and deconditioning.

For respiratory symptoms treatment was provided in order to relieve symptoms and improve function. As all the above patients had dry cough with no secretions, interventions were directed to reduce hypoxemia and relieve dyspnoea.

Early mobilization with a focus on returning to functional activities helped in reducing the length of hospital stay. General mobility exercises prevented muscle weakness and improved exercise capacity. Exercises were progression to bedside mobility, walking for short distances with progressive increase in distance and stair climbing followed by the strengthening of upper limbs and lower limbs in HDU with adequate rest periods. Exercises helped to optimize oxygen transport by improving alveolar ventilation and V/Q matching and also in maintaining normal fluid distribution in the body and also helped in reducing the fear of activity. ${ }^{(15)}$

All the patients showed significant improvement in spite of having comorbidities and moderate to severe infection with physiotherapy interventions, proving the vital role of physiotherapy in COVID 19. Such positive outcomes encourage the doctors to work with more dedication and include physiotherapy as preventive and curative treatment along with medical management for every patient with COVID 19.

\section{ABBREVIATIONS}

ARDS: Acute Respiratory Distress Syndrome

ACE2: Angiotensin-Converting Enzyme-2

CARP: COVID Awake Repositioning Protocol

CRP: C - reactive protein

FiO2: Fraction of Inspired Oxygen

HDU: High dependency unit

Mcg/L: Microgram per litre

NRS: Numerical rating scale

NIV: Non Invasive Ventilation

RT-PCR: Reverse Transcription

Polymerase Chain Reaction

SPO2: Saturation of Peripheral Oxygen

Acknowledgement: None

Conflict of Interest: None

\section{Source of Funding: None}

\section{REFERENCES}

1. Marco Cascella, Michael Rajnik, Arturo Cuomo et al: Features, Evaluation and Treatment Coronavirus (COVID-19). Stat Pearls; 2020

2. Peter Thomas, Claire Baldwin, Bernie Bissett et al: Physiotherapy management for COVID-19 in the acute hospital setting: clinical practice recommendations. $\mathbf{J}$ Physiotherapy; 2020-66: 73-82.

3. Mahesh Jayaweera, Hasini Perera, Buddhika Gunawardana et al. Transmission of COVID-19 virus by droplets and aerosols: A critical review on the unresolved dichotomy. Environ Res. 2020 Sep; 188: 109819. doi: 10.1016/j.envres.2020.109819.

4. NHS: Study suggests new coronavirus may remain on surfaces for days; 2020

5. Nancy $H$ Leung, Transmissibility and transmission of respiratory virus; Nature Reviews Microbiology; 2020

6. Robert Manson; Pathogenesis of COVID-19 from a cell biology perspective Robert J. Mason, European Respiratory Journal 2020; 55: 2000607 

case series.

7. Symptoms of Coronavirus: Centres for Disease Control and Prevention, 2020

8. Shima Behzad, Leila Aghaghazvini, Amir Reza Radmard et al, Extra pulmonary manifestations of COVID19: Radiologic and clinical overview; Clin Imaging ,2020;66: 35-41.

9. Renato Fraga Righetti, Mirian Akemi Onoue et al, Physiotherapy Care of Patients with Coronavirus Disease 2019 (COVID19) - A Brazilian Experience: Sao Paulo; June 2020

10. Angelo Carfì, MD; Roberto Bernabei MD; Persistent symptoms in patients after acute COVID 19, JAMA 2020; 324(6):603-605

11. Chhaya V Verma, Rachna D Arora, Jaimala V Shetye et al, Guidelines of physiotherapy management in acute care of COVID-19 at dedicated COVID center in Mumbai. J Indian Assoc Physiotherapy; 2020:14:55-60.
12. https://covidprotocols.org/protocols/clinicalcourseand-epidemiology.

13. Mueller AL, McNamara MS, Sinclair DA. Why does COVID-19 disproportionately affect older people, aging 2020; 12 (10):9959-81.

14. COVID Awake Repositioning Protocol; (CARP). Resuscitation \& Acute Critical Care, Janus General Medicine; 2020.

15. Pathmanathan N, Beaumont N, Gratrix A. Respiratory physiotherapy in the critical care unit. Continuing Educ Anaesthesia Crit Care Pain. 2015; 15(1):20-5.

How to cite this article: Wakde G, Patil P, Jadhav $S$ et.al. Physiotherapy management of patients with COVID-19 infection in a tertiary care setup- a case series. Int J Health Sci Res. 2021; 11(5): 219-225. DOI: https://doi.org/ 10.52403/ijhsr.20210535 